\title{
Las secuelas sociales de la polio: los inicios del movimiento asociativo en España (1957-1975)
}

\author{
Juan Antonio Rodríguez Sánchez (*) \\ $\left(^{*}\right) \quad$ Área de Historia de la Ciencia. Universidad de Salamanca. \\ jarshm@usal.es
}

Dynamis

[0211-9536] 2012; $32(2): 391-414$
Fecha de recepción: 17 de octubre de 2011

Fecha de aceptación: 20 noviembre de 2011

SUMARIO: 1.-Introducción. 2.-La Asociación de Lucha contra la Poliomielitis (ALPE). 3.-La Fraternidad Católica de Enfermos y Minusválidos. 4.-Enfermedad y minusvalía: perspectivas asociativas. 5.- Los problemas de las personas con discapacidad. 5.1.-Educación. 5.2.-La formación profesional e inserción laboral. 6.-Formas de socialización. 6.1.-La pedagogía activa. 6.2.-Los campamentos y colonias. 7.-Conclusiones.

RESUMEN: La respuesta social en España ante la epidemia de poliomielitis se vio condicionada por las limitaciones impuestas por el régimen dictatorial. Las primeras asociaciones que surgieron fueron afines al sistema político o se enmarcaron en los movimientos seglares de la Iglesia católica. Entre los primeros se encuentra la Asociación de Lucha contra la Poliomielitis (ALPE) y entre los segundos la Fraternidad Católica de Enfermos y Minusválidos. El objetivo de la investigación es el análisis de sus idearios, características organizativas y actividades, a fin de comprender el proceso de socialización de las personas con secuelas de poliomielitis y su asunción de unos valores y rasgos identitarios. Ambas asociaciones ofrecen un claro contraste tanto en el funcionamiento asociativo planteado como en el modelo de discapacidad asumido, en clara transición del modelo médico al social. Ofrecer servicios o enseñar a reclamarlos fue otra de las disyuntivas detectadas. Más trascendente fue la transmisión de un modo de sociabilidad (a través de equipos diocesanos y campamentos) que incorporó prácticas democráticas y formó líderes que tendrían protagonismo en el asociacionismo de personas con discapacidad a partir de la transición.

PALABRAS CLAVE: Poliomielitis, discapacidad, asociacionismo, religión, ideología.

KEY WORDS: Poliomyelitis, disability, associationism, religion, ideology. 


\section{Introducción $(*)$}

La constatación en España, a principios del siglo XXI, del rápido deterioro neurológico que se estaba produciendo en algunas personas que fueron afectadas en su infancia por la poliomielitis (lo que se conoce como síndrome postpolio), llevó a éstas a percibir claras deficiencias en la atención sociosanitaria recibida, perfectamente diferenciadas de las que pudiesen tener otros grupos con discapacidades motoras ${ }^{1}$. La conciencia de unas reivindicaciones específicas alentó el resurgir de un movimiento asociativo con un perfil identitario concreto y una memoria colectiva, que - aunque fragmentada y diluida en la de la lucha por la integración social plena de las personas con discapacidad-comenzó a reconstruirse a partir del recuerdo de unas vivencias escasamente comunicadas, cuando no voluntariamente silenciadas ${ }^{2}$.

Las actitudes dentro del actual movimiento asociativo polio-postpolio (ya sean de liderazgo, participación activa o, incluso, rechazo) están relacionadas con experiencias previas, siendo las más significativas las que se enmarcan en la transición a la democracia. Sin embargo, los testimonios recogidos en el curso de nuestra investigación han señalado de forma significativa (y casi unánime) el contacto con movimientos asociativos anteriores vinculados a la Iglesia católica, concretamente a la Fraternidad Católica de Enfermos, a la que coloquialmente hacen referencia como «la Frater».

(*) Trabajo realizado en el marco del proyecto «De la experiencia individual al movimiento asociativo: ideologías y activismo en la configuración de los movimientos reivindicativos de las personas afectadas por polio y síndrome post-polio», HAR2009-14068-C03-03 financiado por el Ministerio de Ciencia e Innovación.

1. La lucha por el reconocimiento del Síndrome Postpolio (SPP) en la CIE ha sido uno de los factores que han potenciado la aparición de investigaciones en historia de la poliomielitis y en la recuperación de la memoria de las personas afectadas. Prueba de ello es el papel que desempeña el SPP en obras que han recuperado esos testimonios, desde la pionera de Sass, Edmund J. Polio's legacy: an oral history. Lanham: University Press of America; 1996 (donde el SPP se incluye difusamente en el capítulo dedicado a los efectos tardíos) a las más recientes de Wilson, Daniel J. Living with polio: the epidemic and its survivors. Chicago: The University of Chicago Press; 2005 y su contribución con Silver, Julie. Polio voices: an oral history from the American polio epidemics and worldwide eradication efforts. Westport: Praeger; 2007.

2. Rodríguez Sánchez, Juan Antonio. De la minusvalía al síndrome postpolio: diagnóstico médico y movimientos asociativos en la creación de una identidad polio/postpolio. In: Porras, María Isabel et al., eds. Transmisión del conocimiento médico e internacionalización de las prácticas sanitarias: una reflexión histórica. Ciudad Real: Universidad de Castilla La Mancha; 2011, p. 147-152. 
Frente a ella encontramos la Asociación de Lucha contra la Poliomielitis (ALPE) que, paradójicamente, pese a su ámbito nacional, sólo fue conocida en Madrid, aunque, como veremos, sus conexiones muestran un área más extensa. Ambas asociaciones constituyen el objetivo de la investigación para, mediante el análisis de sus idearios, características organizativas y actividades, comprender el proceso de socialización de las personas con secuelas de poliomielitis y su asunción de unos valores y rasgos identitarios que habrían de marcar futuras reivindicaciones y formas de relación.

Esta respuesta asociativa ante la poliomielitis podemos considerarla específica de las circunstancias sociopolíticas españolas: la dictadura y el factor católico. En otros países (como Estados Unidos o Canadá), en los que la epidemia tuvo una incidencia mayor y más temprana, se generaron movimientos al amparo de la beneficencia y la religión, pero surgieron también instituciones estatales y asociaciones civiles de lucha contra la polio, incluidas las de personas afectadas ${ }^{3}$. En España, sin embargo, no existió ese organismo específico contra la poliomielitis aunque fueron asumidas responsabilidades preventivas, asistenciales y, tardíamente, de recuperación funcional.

Las dos asociaciones que analizaremos no fueron las únicas, aunque sí las más influyentes, y el estudio de otras - como la Asociación Nacional de Inválidos Civiles (ANIC) o Auxilia- podrán ampliar y matizar lo aquí expuesto ${ }^{4}$. La Fraternidad y ALPE muestran especial relevancia para

3. Ballester Añón, Rosa. Reseña ensayo. Entre la metáfora y la realidad. Discapacidad e identidad en la historia de la poliomielitis. Dynamis. 2008; 28: 419-425 nos ofrece una revisión de la historiografía sobre la polio en la que se pone de manifiesto la atención dedicada a la National Foundation for Infantile Paralysis estadounidense. Para Canadá, Caron, Pierrette. «Poliomyelitis - A history». In: Aitken, Sally; D'Orazio, Helen; Valin, Stewart, eds. Walking fingers: the story of polio and those who lived with it. Georgetown: Véhicule Press; 2004, p. 17-28 refiere el papel de órdenes religiosas, asociaciones católicas y asociaciones filantrópicas. El decisivo papel del Rotary International en la erradicación de la polio en Pigman, Herbert A. Conquering polio. Evanston: Rotary International; 2005. Para la aplicación de su programa PolioPlus en América Latina: Nascimento, Dilene Raimundo; Cueto, Marcos; Ponce Maranhao, Eduardo; Sobti, Deepak. A erradicaçao da poliomielite na América Latina: comparando Brasil e Peru. In: Nascimento, Dilene Raimundo, eds. A história da poliomielite. Rio de Janeiro: Garamond; 2010, p. 161-176.

4. A éstas podrían añadirse otras muchas, reconocidas por los propios movimientos asociativos como vinculadas con la discapacidad: Hospitalidad de Lourdes, Cáritas, Scouts, Amigos de los Enfermos, Legión de María. Fraternidad. Boletín Nacional para Responsables y Consiliarios, 1972, p. 8. Véase también Fraternidad Católica de Enfermos. El enfermo en la Iglesia. Madrid: Bruño; 1971, p. 65-71. 
conocer los entornos de socialización de los adolescentes afectados por la poliomielitis, condicionados por la transformación del nacionalcatolicismo en propuestas organizativas dirigidas a la juventud desde la oficialidad más vinculada al falangismo o desde un renovado papel del seglar católico abocado a las críticas al régimen político. Dos propuestas que mostraban las tensiones y cambios en la percepción de la discapacidad, con resistencias notables a abandonar un modelo benéfico-asistencial, paternalista y medicalizado ${ }^{5}$.

Es preciso también contextualizar estos cambios con la datación epidemiológica de la poliomielitis en España. Precedida por los brotes de 1942-43, la mayor incidencia de la infección en España se produjo a partir de 1950 y duró hasta 1963, año de inicio de las campañas de vacunación masiva con vacuna oral, lo que nos ofrece un significativo aumento en la proporción que, en el conjunto de las discapacidades motoras, ocupaba la poliomielitis como causa. Un grupo numeroso con una característica diferencial significativa: la presencia de la discapacidad desde los primeros años de vida. De este modo, la poliomielitis, como problema en la infancia, limitó (según el grado de afectación) las posibilidades de acceso a la educación reglada y condicionó la inserción en el mundo laboral y los entornos habituales de sociabilidad. Condiciones que confieren mayor relieve a estas asociaciones, no tanto por la labor educativa de alguna de ellas, sino por la transmisión de pedagogías y formas de relación.

Frecuentemente se ha expuesto la dificultad y retos para el estudio de los movimientos seglares ${ }^{6}$, algo a destacar en el caso del estudio de la Fraternidad Católica de Enfermos. La ausencia total de bibliografía crítica resulta aún más llamativa si tenemos en cuenta la rápida extensión del movimiento en las décadas centrales del siglo XX, no sólo en Europa sino

5. Hirsch, Karen; Hirsch, Jerrold. La identidad de la discapacidad en la era postmoderna. Historia y Fuente Oral. 1995; 1 (13): 7-14. Albrecht, Gary L.; Seelman, Katherine D.; Bury, Michael, eds. Handbook of disability studies. London: Sage Publications; 2001. Una revisión bibliográfica sobre discapacidad y los diferentes modelos de discapacidad puede verse en: Martínez Pérez, José. Consolidando el modelo médico de discapacidad: sobre la poliomielitis y la constitución de la Traumatología y Ortopedia como especialidad en España (1930-1950). Asclepio; 2009, 61 (1):117-142 y Martínez Pérez, José. Discapacidad: evolución de conceptos. In: Rodríguez Sánchez, Juan Antonio, ed. La memoria paralizada: identidades y vivencias de la poliomielitis y el síndrome post-polio. Salamanca: Ediciones USAL (en prensa).

6. Serrano Blanco, Laura. El interés historiográfico de los movimientos de apostolado seglar para la investigación del tardofranquismo y el estado de conservación de las fuentes para su estudio. Hispania Sacra. 2001; 53: 251-266. 
también en América ${ }^{7}$. Ni las ambiciosas historias de la Iglesia ni los extensos diccionarios y enciclopedias recogen a la Fraternidad. En el caso de España apenas una mención en el Diccionari d'història eclesiàstica de Catalunya ${ }^{8}$. A ello debemos añadir las dificultades para rastrear fuentes archivísticas o encontrar colecciones hemerográficas específicas completas, acentuadas por una presencia insignificante en la prensa general de la época ${ }^{9}$.

Para ALPE se repiten los problemas heurísticos con un complejo acceso a las fuentes archivísticas y diseminación de las revistas que editaron. Sin embargo, la vinculación de su directiva a la familia del dictador, Francisco Franco, propició una aparición constante en los medios de comunicación y una posibilidad de reconstrucción de sus actividades mediante la prensa general.

En ambos casos han sido, sin embargo, los testimonios orales los que han permitido conocer la recepción y consecución de los objetivos de estas asociaciones, mostrando posturas eclécticas y pragmáticas frente a presumibles adoctrinamientos.

\section{La Asociación de Lucha contra la Poliomielitis (ALPE)}

El primer intento de creación de una asociación de lucha contra la poliomielitis partió de Cáritas Diocesana ${ }^{10}$, en vísperas de la celebración de la festividad del Corpus Christi, designado como Día Nacional de Caridad ${ }^{11}$. El 19 de junio de 1963, la Asociación Española de Lucha contra la Poliomielitis se presentaba a sí misma ante los medios de comunicación como:

\footnotetext{
7. Comisión Nacional. Fraternidad Católica de Enfermos y Disminuidos Físicos. Madrid: Bruño; 1971, p. 47-57. Boillon, Pierre. El Padre François y la Fraternidad. S.I. Fraternidad Cristiana de Enfermos y Minusválidos; 1992. Frater Intercontinental. Associations Catholique des Personnes Malades et Handicapees. Conseil Pontifical pour la Pastorale des Services de la Santé. Disponible en: Disponible en: http://www.vatican.va/roman_curia/pontifical_councils/hlthwork/documents/ rc_pc_hlthwork_doc_26051997_fraternity_it.html [citada 20 Oct 2011].

8. Masachs, Maite. «Fraternitat Cristiana de Malalts i Minusvàlids». In: Diccionari d'història eclesiàstica de Catalunya. Barcelona: Generalitat de Catalunya-Editorial Claret; 2003, vol. 2, p. 223-224.

9. La Fraternidad no perteneció en sus primeras décadas ni a Acción Católica ni a la UNAS. Como movimiento independiente las principales fuentes son cuadernillos en ciclostil sin ISSN o registro.

10. López Castellano, Fernando. Las raíces históricas del Tercer Sector. Madrid: Fundación ONCE; 2005, p. 129-132.

11. ABC. 20 Jun 1962: 32.
} 
«una entidad de carácter benéfico-social que se propone apoyar la lucha contra la poliomielitis y sus secuelas, realizando una labor asistencial en todos sus aspectos, al mismo tiempo que velará por los intereses espirituales, culturales, morales, económicos y sociales de los que contraigan la enfermedad» ${ }^{12}$.

De esta forma secundaba la labor del Estado fundamentalmente en la vacunación y recuperación de personas afectadas. La prensa resumía y matizaba lo que figuraba en sus primeros estatutos ${ }^{13}$ y añadía que, para conseguir sus fines, contaba con la colaboración de Cáritas Nacional y del propio Estado $^{14}$, así como de la ANIC y personalidades médicas y damas significadas en actividades benéficas, todos bajo la presidencia del Duque de Alba.

Hay que subrayar que el reconocimiento legal surgía previamente a la aprobación de la ley de asociaciones de $1964^{15}$, es decir, se acogía al Decreto de 1941 que derogaba la Ley de Asociaciones de 30 de junio de 1887 y sólo permitía - además de las asociaciones del Movimiento y de la Iglesia- asociaciones voluntarias afines al régimen político ${ }^{16}$. Esta afinidad política sería mucho más manifiesta en los siguientes años y explican el apoyo con que pudo contar ALPE para poner en marcha sus proyectos. En 1967 encontramos en prensa la primera referencia al cambio de presidencia en ALPE, si bien con una figura especial, no contemplada en los estatutos de 1964, llamada «Presidenta de la Junta de Damas» ${ }^{17}$. Este cargo lo desempeñaba Isabel de Cubas y Gerdtzen, condesa de Morata de Jalón por su matrimonio con Andrés Martínez-Bordiú Ortega y, por tanto, concuñada de Carmen Franco, hija del dictador ${ }^{18}$. Esta relación familiar es importante

12. ABC. 21 Jun 1963: 48.

13. Asociación Española de la Lucha contra la Poliomielitis. Estatutos. Madrid, 1964, pp. 3-4.

14. ABC. V, n. 12 .

15. Ley 191/1964, de 24 de diciembre, BOE de 28-12-1964, n. 311. Pelayo Olmedo, J. D. El derecho de asociación en la historia constitucional española, con particular referencia a las leyes de 1887 y 1964. Historia Constitucional (revista electrónica); 2007, 8: 95-122. Disponible en: http://www.historiaconstitucional.com/index.php/historiaconstitucional/article/view/33/24 [citada 29 Ene 2011].

16. Linz, Juan José, La realidad asociativa de los españoles. In: Sociología española de los años setenta. Madrid: Confederación Española de Cajas de Ahorro; 1971, p. 307-348. Pérez Díaz, Víctor. El retorno de la sociedad civil. Respuestas sociales a la Transición Política, la crisis económica y los cambios culturales en España 1975-1985. Madrid: Instituto de Estudios Económicos; 1987, p. 435. Maza Zorrilla, Elena. Panem et circenses. Cultura asociativa en el franquismo. Alcores. 2008; 6: 83-112.

17. ABC. 1 Dic 1967: 57.

18. ABC. 28 Oct 2008: 66 . 
para valorar los circuitos de influencia de la asociación durante el tardofranquismo y el posicionamiento ideológico de sus publicaciones durante la transición democrática ${ }^{19}$.

Las primeras apariciones asiduas en prensa de Isabel de Cubas se vinculan a esta presidencia de la Junta de Damas y a la campaña emprendida por el periódico $A B C$ para vender un número especial cuyos beneficios se destinasen a la Ciudad de San Juan de Dios de Sevilla para niños «subnormales» (según la terminología de la época) ${ }^{20}$. A partir de esa campaña, y durante las décadas siguientes, ALPE e Isabel de Cubas aparecen unidas de forma inseparable, hasta el punto de ofrecer una imagen de la primera como fundación benéfica de la segunda, llegando a plasmar su título nobiliario en la Escuela de Cerámica «Condesa de Morata» y despertar panegíricos necrológicos que superaban la desmesura para caer en la mentira al afirmar que «al frente de ALPE consiguió que la terrible polio quedara completamente erradicada en España» ${ }^{21}$.

\section{La Fraternidad Católica de Enfermos y Minusválidos}

«La Fraternidad de Barcelona no ha querido vivir nunca de la propaganda de las miserias y de la fachada de los éxitos periodísticos. A causa de esta posición, tan incomprensible para algunos: No ha contado nunca con ninguna clase de apoyo oficial ni ha gozado de la protección de personalidades de título, como otras organizaciones. No ha dispuesto de medios económicos porque los enfermos no pagan cuotas, ni hay protectores fijos. No ha tenido hasta ahora, que florece el esfuerzo personal de todos, un Local Social propio, ni siquiera una habitación que sirviera de oficina» ${ }^{22}$.

El incisivo comentario, publicado en la revista Vida Fraterna, marca algunas de las diferencias entre aquella asociación cívica de carácter nacional

19. Hemos podido identificar tres publicaciones periódicas vinculadas a ALPE. Cronológicamente, la primera fue la Revista Española de Subnormalidad, Invalidez y Epilepsia (1970), órgano técnico de ALPE. Las dos siguientes iban dirigidas a un lector joven: El enchufe (1975) y Masválidos (1978)

20. ABC. 1 Dic 1967: 57.

21. ABC. 28 Oct 2008: 66 .

22. Vida Fraterna. 1965; 6. Esta revista ciclostilada, como era habitual en la época, no tiene paginación. 
(aunque con una proyección eminentemente local) y este movimiento más veterano vinculado a la Iglesia católica.

La Fraternidad Católica de Enfermos se creó en Verdún (Francia) en 1942 por la iniciativa del Padre Henri François y se extendió por Francia, consiguiendo su reconocimiento nacional en 1958 por la Conferencia Episcopal Francesa ${ }^{23}$. La Fraternidad estaba concebida como movimiento especializado de apostolado seglar, que buscaba la evangelización entre las propias personas enfermas o con discapacidades. Este aspecto convertía a la Frater, como popularmente se la conoció, en una auténtica forma de asociacionismo ${ }^{24}$ de personas con discapacidad, pues los situaba como miembros activos y no exclusivamente como receptores de la beneficencia emanada de una élite sana.

La Fraternidad no fue reconocida por la Conferencia Episcopal Española hasta julio de $1970^{25}$, es decir, teniendo aún muy reciente la crisis y desmantelamiento de la Acción Católica y en una fase de ambigüedad de la jerarquía eclesiástica previa a su posicionamiento menos complaciente con el Régimen a partir de $1973^{26}$. La Fraternidad no formaba parte de la

23. Comisión Nacional, n. 7, p. 14-15. Boillon, n. 7, p. 34, indica que hasta 1965 no fue integrada en el organigrama de la Iglesia de Francia.

24. El concepto asociacionismo no implica su funcionamiento formal o reconocimiento legislativo como asociación, algo que la Fraternidad rechazó, marcando su carácter de movimiento y no de asociación con personas afiliadas que pagasen cuotas. Véase M. François [François, Henri] Lo que no puede cambiar en la Fraternidad. Fraternidad. Boletín Nacional. 1970, p. 7.

25. Fue aprobada, como asociación de ámbito nacional, por la XII Asamblea Plenaria de la Conferencia Episcopal (del 5 al 11 Jul 1970; Fol. Actas 12). Guía de la Iglesia Católica en España. Nomenclátor 2006. Madrid: EDICE-Conferencia Episcopal Española; 2006, p. 223.

26. Si la historiografía del nacionalcatolicismo ha sido enfocada bien desde la teología, bien desde la ideología: (Botti, Alfonso. Cielo y dinero. El nacionalcatolicismo en España (1881-1975). Madrid: Alianza Universidad; 1992, p. 166-174); algo similar cabe decir para los estudios sobre la Acción Católica y, los casi inexistentes, sobre otros movimientos de apostolado seglar: Montero García, Feliciano. La Iglesia y la Transición. Ayer. 1994; 15: 223-241. Ante las frecuentes referencias que efectuaré especialmente a la crisis de la Acción Católica me limitaré a reseñar aquí algunos de los trabajos representativos, empezando por los estudios de Montero García, Feliciano. La Acción Católica y el franquismo. Auge y crisis de la Acción Católica especializada en los años sesenta. Madrid: UNED; 2000 y La Iglesia: de la colaboración a la disidencia (1956-1975). Madrid: Ediciones Encuentro; 2009. Callahan, William J. La Iglesia Católica en España (1875-2002). Barcelona: Crítica; 2003 (especialmente p. 379-423). O la enciclopédica colaboración de los expertos: Laboa, Juan María; Díaz Salazar, Rafael. Medio siglo de historia de la Iglesia española. In: Neuvecelle, Jean. Pío XII y Juan XXIII. Fliche, Agustín; Martin, Víctor, dirs. Historia de la Iglesia. Valencia: EDICEP. 1984, 27 (2): 483-571. O bien obras de referencia por su erudita aportación documental como la de Cárcel Ortí, Vicente. Pablo VI y España. Fidelidad, renovación y crisis (1963-1978). Madrid: BAC, 1997 (especialmente p. 
Acción Católica y, de hecho, en esos momentos se planteaba su pertenencia a ella o bien ser un movimiento independiente dentro de la Unión Nacional de Apostolado Seglar (UNAS) ${ }^{27}$, pero, como veremos, su organización y filosofía eran la misma. No es de extrañar, por tanto, la prevención de la Conferencia y la negativa, por parte de Morcillo y Guerra Campos, a un encuentro con la Fraternidad y Mn. Henri François durante su estancia en Madrid para la IV Asamblea Nacional ${ }^{28}$.

Para ese entonces el movimiento llevaba quince años de desarrollo en España, principalmente en Levante y Cataluña. Con una cronología discutida por los propios integrantes (que marcan su inicio entre 1956 y 1959, en Denia o Barcelona) y asumiendo la reconstrucción más completa ${ }^{29}$ se puede considerar su origen en el contacto directo con el movimiento francés y el padre Cazenave, de Lourdes, durante una tradicional peregrinación diocesana barcelonesa a aquel santuario el año 1957. En las navidades de ese mismo año se creaba en Barcelona la Hermandad Católica de Enfermos. En la peregrinación del año siguiente se sumaron al grupo personas de Valencia y Gerona, diócesis en las que se constituyó el movimiento en 1958. El 30 de marzo de 1962 se aprobaron los estatutos de la Fraternidad Católica de Enfermos de Barcelona por el arzobispo de la archidiócesis y el 10 de septiembre del año siguiente fue reconocida como persona jurídica. Desde los núcleos barcelonés y valenciano el movimiento se expandió al resto del país, conservando una influencia manifiesta pese al desarrollo del núcleo madrileño y el control central producido a partir de 1967.

603-626) y la colección documental y testimonial de Guerra Campos, José. Crisis y conflicto en la Acción Católica Española y otros órganos nacionales de apostolado seglar desde 1964. Madrid: ADUE; 1989. Artículos y otros trabajos de indudable valor pero con una perspectiva más teológica serán citados oportunamente.

27. Vida Fraterna. 1970; 33-34. Estas reticencias seguían presentes en 1974, como se desprende de un escrito del Padre François en que abordaba los problemas para encuadrar a la Fraternidad en los ámbitos ya existentes: «¿Acción Católica especializada? No, que hacen reuniones de masas». Boillon, n. 7, p. 53.

28. Fraternidad. Boletín Nacional. 1969, p.4.

29. Vida Fraterna. 1964; n 6. Esta cronología publicada en la revista sirvió de base para el capítulo de Júlia Martínez, Una sociedad muy oprimida. In: Vilà i Mancebo, Antonio, coord. Crónica de una lucha por la igualdad. Apuntes para la historia del movimiento asociativo de las personas con discapacidad física y sensorial en Catalunya. Barcelona: Fundació Institut Guttmann-Generalitat de Catalunya; 1994, p. 27-34. En el mismo volumen aparecen comentados estos hitos por Maestre, Vincenç-Antoni. Resumen histórico, pp. 37-41. 
La Fraternidad surgía de las renovadoras ideas eclesiológicas francesas, una teología progresista anticipadora de los cambios que habría de introducir el Concilio Vaticano II (1962-1965), que desde una visión de la Iglesia como comunidad de creyentes asignaba un nuevo papel al seglar, relacionado con el compromiso temporal y la justicia social ${ }^{30}$. La Carta de la Fraternidad dejaba plasmada su ideología en ocho principios que fueron reformulados en la reunión de su Comité Internacional, en París en 1970, para reducirlos a siete, divididos en tres espíritus, dos objetivos y dos medios que «dan vida a la Fraternidad» ${ }^{31}$. Los llamados «medios» nos permiten analizar su estructura organizativa y las tensiones generadas en su implantación en España. «La Fraternidad está vitalizada por equipos de responsables enfermos y disminuidos físicos» $\mathrm{y}$ «recibe la orientación vital cristiana especialmente de los consiliarios», eran esos principios sexto y séptimo del movimiento, los «medios» ${ }^{32}$.

Estas figuras básicas en el funcionamiento diocesano (los responsables y los consiliarios), representaban respectivamente a los seglares y a los clérigos, éstos últimos nombrados por la autoridad correspondiente, en tanto que un procedimiento democrático permitía la elección de responsables, aunque debían recibir la aprobación de la autoridad eclesiástica. A medida que el movimiento se fue extendiendo ganó en complejidad y surgieron órganos de representación regionales y nacionales ${ }^{33}$.

Parcialmente democrático, los integrantes del movimiento sintieron bien pronto que la presencia de los clérigos era excesiva. La VI Asamblea Nacional, celebrada en Ávila en 1970, fue el detonante y, en una crónica, publicaron su protesta: «No nos gustó (...) que todos los temas los dieran sacerdotes. ¿No hay seglares preparados? [...] que en los coloquios los curas monopolizaran el diálogo casi por completo» ${ }^{34}$. Júlia Monfort, responsable del Boletín Nacional, publicó una carta a los consiliarios a quienes reconocía su labor pero les recordaba que «vuestra misión no es mandar, sino formar. Y la gente sólo se forma actuando, tomando decisiones,

30. Callahan, n. 26, p. 382-383. Serrano, n. 6, p. 257-259.

31. La nueva Carta de la Fraternidad Católica de Enfermos. Madrid, 1971, p. 24. Inicialmente la Carta se redactó en 1951 con esos ocho principios que aparecen glosados en Boillon, n. 7, p. 27.

32. La nueva Carta, n. 31, p. 19.

33. Vida Fraterna. 1970; 33-34; Fraternidad [1981], p. 23.

34. Fraternidad. Boletín Nacional. 1970: 4. 
equivocándose» ${ }^{35}$. En la siguiente Asamblea Nacional, a instancias de la Comisión Episcopal del Apostolado Seglar ${ }^{36}$, se decidió suprimir el voto de los consiliarios diocesanos, lo que daba un mayor peso a los seglares y con ello a las mujeres, quienes asumieron funciones de responsabilidad desde la creación de la Fraternidad ${ }^{37}$.

Sin embargo, la supresión del voto de los consiliarios diocesanos se tradujo también en una pérdida de representatividad de Cataluña y Levante, las más numerosas y significadas en la defensa del compromiso con la realidad social, derivado de la asunción del método de revisión de vida ${ }^{38}$, y portavoz en las páginas de sus publicaciones (como Vida Fraterna) del idioma catalán y de un sentimiento de identidad nacional. Simultáneamente, entre 1968 y 1974, tanto Responsable como Consiliario Nacional, aunque elegidos, fueron de Madrid y, pese a que el Equipo Nacional pretendió evitar la imagen de centralismo con adjuntías periféricas, las acciones desarrolladas sugerían un mayor control jerárquico sobre el movimiento ${ }^{39}$.

\section{Enfermedad y minusvalía: perspectivas asociativas}

El aumento de la poliomielitis cambió progresivamente el panorama de la discapacidad física, mostrando no sólo diferentes necesidades, sino también nuevas formas de comprender y rechazar el concepto de minusvalía. Los niños de la polio crecieron con deficiencias motoras, más o menos severas, y descubrieron que éstas ni eran enfermedades, ni tenían por qué convertirse en limitaciones. De esta forma aportaron una experiencia, en el período estudiado, que cuestionaba la pertinencia del rol tradicional

\footnotetext{
35. Fraternidad. Boletín Nacional. 1970: 16.

36. Fraternidad. Boletín Nacional. 1971: 3.

37. Esto fue reconocido dentro del propio movimiento por Sanz Falces, médico y responsable diocesano de Madrid. Fraternidad. Boletín mensual. 1966, julio-agosto, n 6. Para el papel de las mujeres en la Acción Católica véase Rodríguez de Lecea, Teresa. Mujer y pensamiento religioso en el franquismo. Ayer. 1995; 17: 173-200. Moreno Seco, Mónica. De la caridad al compromiso: las mujeres de Acción Católica (1958-1968). Historia Contemporánea. 2003; 26: 239-265.

38. Serrano, n. 6, p. 258. Fullana, Pere; Montero, Feliciano. Los modelos educativos juveniles del movimiento católico en España (1868-1968). Historia de la Educación, 2003-2004, 22-23: 33-51 (35).

39. Fraternidad [1981]: 23.
} 
asumido por el discapacitado y auspiciaba emergentes posturas reivindicativas que demandaban responsabilidad institucional; una pugna entre la visión que consideraba que la persona con discapacidad debía adaptarse al medio para integrarse en él y la inconformista que reclamaba el cambio del medio para que así se respetasen los derechos de todas las personas. Nos encontramos, por tanto, ante la eclosión en España del debate entre un modelo individual y médico de la discapacidad y el pujante modelo social de la misma. Este posicionamiento no fue tan evidente para las asociaciones estudiadas y ambas vivieron un proceso de cambio, no exento de ambigüedades, claramente condicionado por las circunstancias políticas y las relaciones con el Gobierno, la Iglesia y sus jerarquías.

Desde la separación explícita de su nombre («de enfermos y minusválidos»), la Fraternidad defendió que las personas con discapacidad no eran enfermos y, en consecuencia, ofreció escasa información de tipo médico, apenas sobre servicios de rehabilitación ${ }^{40}$ y debido al claro sesgo, en Madrid, de un médico como responsable diocesano ${ }^{41}$. Sin embargo, aunque se opuso a las actitudes sociales -incluidas las de la propia Iglesia- ${ }^{42}$ centradas en el paternalismo y la mentalidad asistencial, dolorista o piadosa ${ }^{43}$, no dejó de propiciar la ambivalente consigna del esfuerzo personal, afín a las advertencias de Pío XII sobre las posturas acomodaticias en los enfermos ${ }^{44}$. Fueron muchos los fraternos que, con el refrendo de algunas encíclicas ${ }^{45}$ y del Concilio Vaticano II, comenzaron a asumir las implicaciones reivindicativas del modelo social de discapacidad y su vinculación con el nuevo sentido eclesiológico en el que el enfermo, como miembro de la Iglesia, compartía con los demás seglares la misión de transformar el medio en

40. Es de destacar la información aparecida en Vida Fraterna. 1964; 2-3, sobre Centros de Recuperación Funcional en Barcelona, Terrasa y Sabadell; así como la información sobre la inauguración del Instituto Guttmann. Vida Fraterna. 1965; 11-12.

41. Luis Sanz Falces, véase como ejemplo Fraternidad. Boletín mensual. 1966. 2 y 3.

42. Fraternidad Católica de Enfermos, n. 4, p. 48.

43. Comisión Nacional, n. 7, p. 9-11. Fraternidad Católica de Enfermos, n. 4, p. 15-16. Vida Fraterna. $1964 ; 6$.

44. Valeri, Luis. Readaptación de inválidos. La Vanguardia. 13 Ene 1963: 11. Cita el discurso de Pío XII de 1954.

45. Mater et Magistra (1961) y Pacem in Terris (1963) tuvieron un papel decisivo en el enfoque del compromiso temporal. Montero, 2009, n. 26, p. 91-98. Montero, 2000, n. 26, p. 77. Laboada; Díaz, n. 26, p. 522. 
que desarrollaba su apostolado ${ }^{46}$. La caridad empezó a ser contemplada en su dimensión socio-política y el continuamente aludido «compromiso temporal» invitaba a la reivindicación como único camino hacia la integración ${ }^{47}$ : «la noción de beneficencia ha de cambiarse por la de reparación o compensación [...] Hoy 1965, hay que transformar la beneficencia por la justicia y su consecuente reparación» ${ }^{48}$.

Pese a que la Carta y la Nueva Carta alentaban el desarrollo integral de los disminuidos físicos, tanto en el orden natural como en el sobrenatural, la Comisión Nacional mostró sus reticencias en asumir las implicaciones reivindicativas últimas de estos objetivos e interpretó este desarrollo integral en su dimensión psicológica ${ }^{49}$. La promoción del desarrollo en el orden natural no pasaba por tanto por facilitar educación, trabajo o rehabilitación, sino por funcionar como grupo de ayuda mutua, ya que aquellos no podían ser vistos como objetivos únicos, pues «sólo son medios para que el disminuido físico adquiera conciencia de su dignidad y de su responsabilidad y se haga capaz de entregarse a otros y a través de ellos a Dios» ${ }^{50}$. La adquisición de los elementos integradores quedaba por tanto en mano de las instituciones y del propio individuo ${ }^{51}$.

Por su parte, el planteamiento fundacional de ALPE la adscribía a un modelo médico de discapacidad, claramente benéfico-asistencial, en el que usaba como referente, tanto en lo clínico como en lo educativo, a la ANIC, con la que superponía en buena medida sus funciones. Su vinculación con los profesionales de la salud fue estrecha tanto en sus órganos directivos, como en las páginas de sus revistas y en diversos proyectos: la Revista Española de Subnormalidad, Invalidez y Epilepsia, primera publicación de ALPE, fue órgano oficial de la Asociación de Amigos del Servicio de Neurología Nicolás Achúcarro.

46. Fraternidad Católica de Enfermos, n. 4, p. 9. Diego Gracia marca como características a destacar de la Fraternidad la de estar compuesta exclusivamente por enfermos y minusválidos y ser un movimiento cristiano entendido como comunidad de base que permite un nuevo tipo de presencia eclesial. Gracia Guillén, Diego. Prólogo. In: Pérez Peñasco, Alfonso; coord. La sanidad española desde la perspectiva del usuario y la persona enferma. Madrid: Fraternidad Cristiana de Enfermos y Minusválidos-Ediciones Encuentro; 1983, p.11-12.

47. Fullana, Montero, n. 38, p. 46. Montero, 2009, n. 26, p. 52-53.

48. Vida Fraterna. 1965; 8.

49. Comisión Nacional, n. 7, p.29.

50. Fraternidad Católica de Enfermos, n. 4, p. 45.

51. Comisión Nacional, n. 7, p. 33. 
La creación del SEREM en 1970 y la aparición de nuevos movimientos asociativos que reclamaban tener voz en las comisiones que durante la transición pretendían legislar la integración social del minusválido, condujeron a un rápido cambio del discurso de ALPE en el que priorizó el concepto de «justicia» sobre el de «promoción», tan presente en la Fraternidad, y consideró que la integración se alcanzaría «sólo el día en que entendamos que $[. .$.$] no es una obra de caridad sino una exigencia que revierte a favor$ de todos, sólo cuando no obremos por mal entendida caridad sino por exigencia de la más simple de las justicias humanas» ${ }^{52}$.

\section{Los problemas de las personas con discapacidad}

\subsection{Educación}

La poliomielitis planteó un problema diferente al de los inválidos civiles adultos: el acceso a la educación. La severidad de las secuelas y el grado de discapacidad condicionaron las posibilidades educativas mucho más que la inteligencia y aptitudes de aprendizaje de las personas afectadas. Las frecuentes intervenciones quirúrgicas determinaron el retraso escolar de la mayor parte de niñas y niños y las barreras arquitectónicas aumentaban el desánimo de cara a afrontar el esfuerzo para una formación superior.

Estos problemas no pasaban desapercibidos para la Fraternidad, quien realizó una encuesta entre sus responsables diocesanos donde se manifestaba que el $7 \%$ no tenía ningún estudio y el $45 \%$ sólo estudios primarios o cultura general ${ }^{53}$. Sin embargo, como queda dicho, la Frater no tenía como objetivo la prestación de servicios, sino el desarrollo como persona del minusválido (la «promoción»), por lo que no se planteó la tarea de paliar ese déficit educativo, en buena medida por su propia defensa de la integración: «No crear escuelas para minusválidos sino procurar que éstos se incorporen a las que ya hay» ${ }^{54}$.

Hasta que Gobierno y sociedad asumieron esos derechos de las personas con discapacidad muchos niños poliomielíticos quedaron sin escolarizar.

\footnotetext{
52. El enchufe. 1976; 1 (6): 1.

53. Vida Fraterna. 1967; 22

54. Fraternidad. Boletín Nacional, 1972, p. 9. Matizado un año antes en Comisión Nacional, n. 7, p. $61-62$.
} 
Desde su concepción como organización benéfico-social, y a semejanza de la ANIC, ALPE tuvo como prioridad la educación: al año de su creación, el Ministerio de Educación Nacional les aprobaba la constitución de un Consejo Escolar Primario y la creación de cuatro escuelas nacionales en Madrid para niñas y niños afectados por la poliomielitis ${ }^{55}$, con ubicaciones provisionales incluso en 1969, en que, como Centro Piloto de la Lucha contra la Poliomielitis, ocupó la planta baja del Colegio Nacional Méjico hasta la década de los ochenta. Aunque las publicaciones refieren un centro educativo mixto, con gimnasio, autobús escolar y plantilla especializada ${ }^{56}$, los testimonios nos presentan un colegio con escasa exigencia en la formación del alumnado ${ }^{57}$, pero con una indiscutible función de acogida para esa infancia rechazada en otras escuelas a causa de las secuelas de la polio ${ }^{58}$. La evolución del Centro Piloto había de quedar condicionada por la disminución de los nuevos casos de polio y por un cambio de actitudes hacia la integración de los niños con discapacidad motora en edad escolar que reconocía como único obstáculo para la misma la barrera arquitectónica ${ }^{59}$.

Los testimonios muestran también una realidad que habría que matizar a partir de dos factores determinantes: la oferta de centros y el grado de discapacidad. La educación primaria contaba con un mayor número de escuelas próximas espacialmente a las personas afectadas, de modo que la negativa a aceptar a un niño poliomielítico podía ser soslayada a través de otro colegio y las barreras arquitectónicas salvadas con la buena voluntad de familia, maestros y compañeros. Sin embargo, para niveles superiores de formación y especialmente los universitarios, la reducción de la oferta implicaba la obligatoria adaptación de la persona a un medio que no estaba concebido para ningún tipo de restricciones de movilidad. La necesidad de transporte público o de vehículo particular adaptado fueron las primeras barreras para acudir a los lugares de formación en los que era frecuente encontrar la ampulosidad arquitectónica que situaba el saber en la cima de grandiosas escaleras.

55. Orden de 26 de febrero de 1964 del Ministerio de Educación. BOE no 71, 23 Mar 1964, p. 3791. ABC. 24 Mar 1964: 49-50.

56. M.A.F. Nuestro Centro Piloto. El enchufe, 1976, 1 (7):12-13.

57. Entrevista a Rosa González Bocuñano, 15 Jul 2011.

58. Entrevista a Braulia Ruiz Moreno, 16 Sep 2011.

59. Gonzalo, José Miguel. Suprimir los ghetos para deficientes. El enchufe. 1976; 1 (6): 5-7. 
«Entonces, la Universidad para mí tenía escalones, pero es que encima escalones sin barandilla, pero los subía. [...]... Y en el metro ¡qué quieres que te diga! ¡Anda que no había escaleras en el metro antes de los ascensores! Tenía que hacer transbordo, tenía que irme con los libros colgados... [...] Que una persona normal tardara media hora en llegar, yo me tiraba hora y media. [...] Si yo, por ejemplo, en vez de poder andar hubiera ido en silla yo no hubiera podido haber estudiado» ${ }^{60}$.

\subsection{La formación profesional e inserción laboral}

La situación laboral de las personas con discapacidad formaba parte del discurso de la Iglesia, del Estado y de las asociaciones, pero siempre cargado de ambigüedad al no ser reconocido como un derecho. Como tampoco lo era cobrar una pensión. El trabajo podía ser interpretado desde una perspectiva terapéutica, pero, tal y como se formulaba, subrayaba que sólo a través de él se podía considerar útil al discapacitado. Las declaraciones de los miembros del Gobierno, incluidas las del propio Jefe del Estado, desvelaban una valoración de las personas con discapacidad como carga social $^{61}$. Una apreciación paradójica, cuando no inconsecuente, por parte de quienes, tras minimizar la importancia de la polio y sus secuelas, no preocuparse de vacunar hasta 1963 y, ni siquiera entonces, hacerlo con eficacia, comenzaban a plantear el trabajo como recuperación de lo invertido en unas personas con discapacidad a las que tampoco se les había ofrecido la posibilidad de una educación básica ni de una rehabilitación y fisioterapia adecuadas ${ }^{62}$.

60. Entrevista a M.F.G.G., 17 Sep 2011.

61. Blanco, Juan Eugenio. La concepción de la invalidez en la Ley de Bases de la Seguridad Social. Vida Fraterna. 1964; 4-5; Perez-Bustamante, Jaime. Franco y los minusválidos. El enchufe. 1976; 1 (6): 35.

62. Ballester Añón, Rosa. La presentación internacional de las campañas de vacunación antipoliomielítica en España (1950-1963). In: Perdiguero Gil, Enrique; Vidal Hernández, J. M., coords. Las vacunas: historia y actualidad. Menorca: Institut Menorquí d'Estudis; 2008, p. 123-138. Martínez Pérez, n. 5. Rodríguez Sánchez, Juan Antonio. Responsabilidades nao asumidas: a poliomielite na Espanha (1954-1967). In: Nascimento, n. 3, p. 195-224. Toledo Marhuenda, José Vicente. La poliomielitis en España (1880-1970) y su impacto sobre el desarrollo de las técnicas en Fisioterapia. Alicante: Universidad Miguel Hernández; 2009. 
La Fraternidad no asumió actividades dirigidas a la formación profesional, aunque era consciente de las necesidades laborales de las personas con discapacidad. Consecuente con la revisión de vida, promovió en 1960 una encuesta sobre discapacidad que arrojó la cifra de 50.000 enfermos crónicos en Barcelona ciudad, de los cuáles un 60\% eran inválidos. De éstos, un 60\% vivía de la familia, un $20 \%$ se acogía a beneficencia, un $4 \%$ era perceptor de pensiones, un $5 \%$ se dedicaba a la venta de cupones, un $3 \%$ trabajaba en empresas y sólo un $1 \%$ en profesiones liberales ${ }^{63}$. Sin embargo, no buscaron soluciones directas para el problema y, aunque sus revistas ofrecieron información sobre ayudas, escuelas de readaptación profesional, ofertas de trabajo y creación de cooperativas ${ }^{64}$, su balance de las experiencias más comprometidas era desalentador ${ }^{65}$.

En el caso de ALPE - aunque la ANIC ya contemplaba la formación profesional mediante un sistema de becas con cargo al Patronato del Fondo Nacional de Protección al Trabajo y contaba con Centros de Formación Profesional en sus diferentes delegaciones provinciales- ${ }^{66}$ una de sus primeras actuaciones fue la capacitación profesional: talleres de imprenta, fotografía, música y relojería en el Hospital de San Rafael (trasladados más tarde a Torrejón) ${ }^{67}$ o el de cerámica en la central de Auxilio Social. Pero, sin lugar a dudas, sería la Escuela de Cerámica «Condesa de Morata» (EC$\mathrm{CM}$ ) la que tendría un carácter emblemático, constatado por la frecuente aparición en prensa de sus exposiciones, artículos sobre su funcionamiento y publicidad de sus productos, así como la abundante información en sus revistas ${ }^{68}$. Esta promoción, siempre según la propia asociación, permitió una venta anual de un millón de piezas ${ }^{69} \mathrm{y}$ una plena inserción laboral de las personas que formaban ${ }^{70}$.

\footnotetext{
63. Vida Fraterna. 1965: 6.

64. Vida Fraterna. 1964; 4-5.

65. Fraternidad. Boletín Nacional, 1972, p. 9-10.

66. El enchufe. 1975; 1 (1): 14.

67. ABC. 14 Feb 1973: 119.

68. ABC. 6 Sep 1978: 107.

69. Masválidos. 1980; 1 (5): 18-21.

70. El enchufe. 1975; 1 (1): 24-25.
} 


\section{Formas de socialización}

\subsection{La pedagogía activa}

La socialización de la juventud fue una constante durante el franquismo y el adoctrinamiento nacionalcatólico fue uno de sus principales objeti$\operatorname{vos}^{71}$. La juventud con secuelas de polio no quedó ajena a estos intereses que, entre humanitarismo y beneficencia, consideraban la conveniencia de formar líderes en este numeroso colectivo. Surgidos antes de la Ley de Asociaciones, los movimientos analizados pautaron su socialización desde entornos afines al régimen político y la Iglesia católica ${ }^{72}$.

Aunque ALPE funcionó como una asociación que gestionaba recursos públicos y privados para invertirlos en prestación de servicios a los poliomielíticos, el modelo excluyó durante mucho tiempo la opinión de los propios afectados y, en el mejor de los casos, pudo ser vista como una asociación de padres ${ }^{73}$. Algo que contrasta con el movimiento especializado que era la Fraternidad y explica cómo en ella se pudo fraguar un aprendizaje diferente de participación asociativa, aunque el mismo condujese a la crítica a la propia organización.

La Fraternidad, al igual que los movimientos especializados de la Acción Católica, había asumido el método del sacerdote flamenco Josep Cardijn, un método inductivo y participativo, conocido como encuesta o revisión de vida, que, a diferencia de los anteriores Círculos de Estudio, partía de la experiencia y no de los documentos de la doctrina social de la Iglesia. El análisis de la realidad social había de conducir al compromiso para transformar esa realidad ${ }^{74}$.

La formación en la Fraternidad quedó claramente estipulada con la publicación por la Comisión Nacional de un pequeño manual para dirigir

71. Ruiz Carnicer, Miguel Ángel. El sistema y la fabricación de un nuevo consenso. In: Gracia, Jordi; Ruiz Carnicer, Miguel Ángel. La España de Franco (1939-1975). Cultura y vida cotidiana. Madrid: Editorial Síntesis; 2004, p. 283-290.

72. Maza, n. 16.

73. Entrevista a Pedro Sergio Moyano, 2 Jun 2011.

74. Fullana, Montero, n. 38, p. 43-47. March Manresa, Miquel; Sureda García, Bernat. La renovación del método educativo en las asociaciones juveniles católicas en los años sesenta del siglo XX. Historia de la Educación. 2003-2004; 22-23: 123-138 (126-129). Montero, Feliciano. Juventudes y política: los movimientos juveniles de inspiración católica en España: 1920- 1970. Studia Historica. Historia Contemporánea; 1987, 5: 105-121 (119). 
una «Campaña de Iniciación» que reforzase los habituales «Cursillos de Iniciación» dirigidos a quienes tomaban contacto con la Fraternidad. La campaña desgranaba los siete puntos de la Nueva Carta de la Fraternidad mediante el método característico de ver, juzgar y actuar ${ }^{75}$. A esto había de unirse un aprendizaje democrático a través del funcionamiento de las Fraternidades y de los equipos, que reclamaba progresivamente un nuevo espacio de sociabilidad desvinculado de los nombramientos eclesiásticos ${ }^{76}$.

La asunción del compromiso temporal tomó forma en acciones directas o a través de la militancia en otras organizaciones. Así, el apostolado entre enfermos abandonó el entorno de la reunión parroquial para convertirse en una labor de reinserción social de las personas discapacitadas. Fue decisiva la campaña ${ }^{77}$ de 1967 con el lema "presencia en el mundo», con que aludían a la visibilización del minusválido a través de las «salidas colectivas», con las que rompían el enclaustramiento domiciliario vivido por muchos y pretendían que la sociedad se acostumbrase a la presencia de personas con discapacidad ${ }^{78}$. Esta actividad ha sido, con el tiempo, definitoria de la Fraternidad tanto para quienes tuvieron responsabilidades en ella, como para las personas con discapacidad que la conocieron más superficialmente ${ }^{79}$.

Consciente de las nuevas respuestas asociativas y su mayor carácter resolutivo ${ }^{80}$, la Fraternidad facilitó los contactos entre organizaciones y aspiró a transmitir su ideario a través de los fraternos que participasen en ellas ${ }^{81}$. La entrevista realizada en Vida Fraterna a Juanita Tuldrá Sanz, la primera Responsable Nacional de la Fraternidad, puede ejemplificar la trayectoria consecuente de algunos de sus miembros. En ella declaraba: «Pertenezco

75. Desarrollo de los principios fundamentales de la Fraternidad Católica de Enfermos: orientaciones para penetrar en su espíritu. Madrid: 1972. March; Sureda, n. 74, p. 129.

76. Vida Fraterna. 1964; 4-5.

77. El sentido de las campañas es explicado por Montero, 1987, n. 74, p. 120: «campañas anuales específicas de cada movimiento, pero coordinadas en objetivos comunes, son el instrumento que guía la acción individual y colectiva de los militantes [...] los temas de las campañas revelan la creciente incidencia social y política de los Movimientos».

78. Vida Fraterna. 1967; 19 y 20.

79. Los testimonios orales que inciden en esta cuestión son muy numerosos y comunes a diferentes diócesis. Como testimonio impreso, de un consiliario, García González, Justo. XXV años de la Fraternidad Cristiana de Enfermos y Minusválidos en la Diócesis de Ávila. Ávila: MARCAM; 1992; o de una persona afectada Riu i Pascual, Maria del Carme. La Coordinadora de Disminuidos Físicos. In: Vilà i Mancebo, n. 29, p. 93-109 (97).

80. Vida Fraterna. 1967: 22. Fraternidad. Boletín Nacional, 1972, p. 8.

81. Vida Fraterna. 1965; 7. 
a la Acción Católica Obrera (HOAC), a la junta de la Asociación Pro Rehabilitación de Inválidos, al consejo directivo de "Auxilia", y como todo enfermo, a la Fraternidad» ${ }^{82}$. La entrevista no sólo retrataba, a través de las preferencias de Tuldrá, a una mujer de ideología claramente progresista, sino que constataba que la Fraternidad prefirió no actuar directamente sino participar en la formación de líderes del movimiento asociativo ${ }^{83}$.

\subsection{Los campamentos y colonias}

A partir de mediados de los cincuenta Falange se había diluido en el Movimiento Nacional, cuya Secretaría General se convertiría en un ministerio a partir de 1957. Tres años más tarde las Falanges Juveniles de Franco se transformaron en la Organización Juvenil Española (OJE) con una imagen scout más adecuada a los cambios sociales, aunque «su principal finalidad siguió siendo la socialización de la juventud en los principios políticos del régimen y la captación de militantes y dirigentes para el Movimiento» ${ }^{84}$. Los campamentos y albergues tuvieron un papel fundamental en ello.

La «infancia y juventud poliomielítica» podía incorporarse a los campamentos generales o a los específicos que organizó ALPE, junto a ANIC y ONCE, en colaboración con la Delegación Nacional de Juventudes por toda la costa española ${ }^{85}$. El testimonio de Pedro Moyano, que intervino en ellos como «mando», da cuenta de esta actividad:

«Estabas, o en campamentos con chicos, en campamentos de lo de la OJE (movimiento juvenil del régimen de entonces), en tiendas de campaña [...] entonces no había otra cosa en España de tema de vacaciones más que eso, no es como ahora, y entonces ¿qué pasaba?... que se llenaba, ¿sabes? [...] Por aquella época llevaban los campamentos chicos puestos por la asociación, que uno de ellos, Inocencio Valdivia, fue presidente de COCEMFE [Confederación Española de Personas con Discapacidad Física y Orgánica] años

\footnotetext{
82. Vida Fraterna. 1965; 8.

83. Díaz Salazar, Rafael. Iglesia, dictadura y democracia. Catolicismo y sociedad en España, 19531979. Madrid: HOAC; 1981, p. 102. Ruiz Carnicer, n. 71.

84. Fernández Hevia, José María. Fuentes documentales para estudio de la política de juventud durante el franquismo: las Delegaciones Provinciales del Frente de Juventudes. AABADOM. 2002: 29-40: 33.

85. El enchufe. 1975; 1 (1): 14. ABC. 17 Ago 1975: 70; El enchufe. 1975; 1 (5): 6. El enchufe. 1976; 1 (9): 6-7.
} 
después, ¿no? [...] Las chicas solían ir a albergues de la Sección Femenina, a otros sitios. [...] Los muy pequeños, porque luego los llevé yo, iban a El Palo, a un barrio de pescadores de Málaga» ${ }^{86}$.

Los campamentos se dirigieron a un amplio espectro de edad que iba de los siete a los 21 años, lo que propició también actitudes más independientes respecto a las pautas clásicas de estas organizaciones, lo que no dejó de generar algún conflicto ${ }^{87}$.

Pero no fue éste un patrimonio exclusivo de las organizaciones ligadas a la Falange y al régimen político, pues hay que recordar la vitalidad del escultismo en España y su adopción por la Iglesia católica para la formación de niños y jóvenes ${ }^{88}$ : Auxilia o la propia Fraternidad no fueron ajenas a este entorno y asumieron el valor del ocio y las vacaciones más allá de las tradicionales peregrinaciones a Lourdes ${ }^{89}$, teniendo además en cuenta que desde finales de los sesenta su composición mayoritaria era de jóvenes sanos con secuelas de polio ${ }^{90}$.

Todos los testimonios recogidos inciden en el valor que campamentos, colonias y albergues tuvieron, pese a la concepción de la época, como espacio de libertad y escapatoria del proteccionismo familiar y paternalismo social, así como forma de establecer relaciones con otros niños o jóvenes con polio en una época en que no existía otro recurso vacacional ${ }^{91}$.

\section{Conclusiones}

ALPE y la Fraternidad enfocaron sus actividades desde diferentes entornos asociativos, los únicos posibles en la década de los sesenta, y desde modelos de concepción de la discapacidad también distintos. En tanto que la primera se vinculó en sus orígenes a las organizaciones afines al régimen franquista y una visión medicalizada e individual de la discapacidad, la segunda surgía al amparo de la Iglesia católica pero desde las renovadoras

\footnotetext{
86. Entrevista a Pedro Sergio Moyano, 2 Jun 2011.

87. Entrevista a Braulia Ruiz Moreno, 16 Sep 2011.

88. Fullana, Montero, n. 38, p. 47-49. March; Sureda, n. 74

89. Vida Fraterna. 1965; 8

90. Así lo reconocen diferentes testimonios como el de Diego Márquez (entrevista realizada el 2 Mar 2010) o el de Martínez, n. 29, p. 28.

91. Entrevista a M.F.G.G., n. 60.
} 
corrientes eclesiológicas francesas anticipatorias del espíritu conciliar y defendía una interpretación más social de la discapacidad. Pese a sus lastres y contextos ambas brindaron algún tipo de beneficio a sus asistidos (educación y formación laboral en el caso de ALPE) y a sus miembros (visibilidad y promoción personal en el caso de Frater). Ninguno de ellos puede ser desestimado pues, como reconocen las personas con poliomielitis, éstos eran los escasos recursos que existían.

En ambos casos y pese a sus enormes diferencias, posibilitaron unos entornos de sociabilidad (campamentos o equipos diocesanos) que crearon vínculos entre las personas afectadas, les dieron visibilidad y les aportaron nuevas ideas sobre la discapacidad, permitiéndoles, en el caso de la Fraternidad, sentir como derechos lo que hasta entonces habían vivido como caridad. La conciencia de la justicia y la reivindicación se fraguaron en un contexto de cambio sociopolítico al que los jóvenes poliomielíticos estaban preparados para contribuir y en el que algunos manifestaron la formación recibida para el liderazgo.

Sin embargo, aunque dirigentes y consiliarios de la Fraternidad pudieron tener claras las funciones que ésta tenía y centrarse en la promoción humana de las personas discapacitadas, para muchos de sus miembros primaba la necesidad de ayuda en problemas $\operatorname{cotidianos}^{92}$ o consideraban que el compromiso temporal debía traducirse en acciones concretas acordes con los cambios sociales. Las críticas se sucedieron en todas las Fraternidades ${ }^{93}$ y condujo al abandono de muchos fraternos, si bien, en unos momentos en que los movimientos seglares habían sido llamados al orden, la frontera entre dimisiones y ceses era sumamente sutil ${ }^{94}$. La Fraternidad enfrentó sus tensiones entre clérigos y seglares, entre consiliarios y responsables, y finalmente vio refrendadas las posturas más comprometidas por el propio giro que la jerarquía eclesiástica adoptó en España ${ }^{95}$. La democracia supuso que los poderes públicos asumiesen nuevas funciones en base al derecho a la igualdad de las personas funcionalmente diversas ${ }^{96}$, por lo que las asociaciones pasaron a centrar sus objetivos en la mentalización social

\footnotetext{
92. Sanz Falces, Luis. Comentando una sugerencia. Fraternidad. 1966; 4.

93. Vida Fraterna. 1965; 7.

94. Un ex combatiente. Mi paso por la Fraternidad. Vida Fraterna. 1968; 29-30.

95. Callahan, n. 26, p. 409-423. Montero, 2009, n. 26, p. 263-336.

96. Guillén, Antonio. La participación. In: Vilà i Mancebo, n. 29, p. 63-69.
} 
o la influencia en las políticas públicas ${ }^{97}$, algo que había sido identitario para la Fraternidad. Sin embargo, al desaparecer sus privilegios asociativos, muchos de sus miembros ya habían encontrado respuesta a sus inquietudes en el amplio abanico de asociaciones que se estaba constituyendo en un contexto laico.

Por su parte ALPE había nacido con la vocación de ser una organización civil con funciones similares a las constituidas en otros países en la lucha contra la poliomielitis, pero su tardía creación - simultánea al inicio de las campañas de vacunación oral masiva- dejaba sin efecto, ya desde su origen, algunos de sus principios. Consciente de su necesidad de adaptarse, lo hizo manteniendo un nombre que iba perdiendo significado en el país, al tiempo que nuevas asociaciones empezaban a ser tenidas en cuenta por el Servicio Social de Recuperación y Rehabilitación de Misnusválidos $(\text { SEREM })^{98}$. El éxito de la vacunación supuso una drástica disminución en el número de niños afectados por polio y, cuando fue inminente el cambio en la forma de gobierno del Estado y la asociación veía peligrar sus apoyos, esos niños afectados entraban en la adolescencia. La aparición de la revista El enchufe, en mayo de 1975, «dirigida a la juventud española» era un claro exponente de cómo ALPE percibía el cambio que se estaba experimentando en la sociedad y en las funciones que como asociación podría desempeñar ${ }^{99}$, avalada por los nuevos apoyos recibidos por su presidenta, Isabel de Cubas, por parte de la monarquía que, considerándola experta interlocutora con el mundo de las personas con discapacidad, la nombraba miembro del Instituto Nacional de Educación Especial ${ }^{100}$.

Sin embargo, tanto la incapacidad de ALPE para integrar como socios de pleno derecho a sus asistidos, como la falta de soluciones a los problemas materiales de las personas con discapacidad por parte de la Fraternidad (excesivamente reticente a asumir las últimas implicaciones del compromiso temporal) acabaron por apartar a quienes en algún momento fueron beneficiarios o simples miembros. La tensión principal para Frater fue la del grupo de ayuda mutua que se resistía a convertirse en asociación, en tanto

97. Casado, Demetrio. Situación y perspectivas del movimiento voluntario en el área de la discapacidad. In: Vilà i Mancebo, n. 29, p. 21-24.

98. En 1974 se celebró Minusval (Conferencia Nacional sobre Integración del Minusválido) y se creó la Comisión Interministerial para la Integración Social de los Minusválidos, aunque no habría de culminar hasta 1982 con la Ley de Integración Social de los Minusválidos (LISMI).

99. El enchufe. 1975; 1 (1): 1.

100. ABC. 29 Jun 1976, p. 88. 
que ALPE anteponía su supervivencia a sus funciones en una época en que la realidad de las personas con secuelas de polio y de los movimientos asociativos en democracia era otra: las personas con discapacidad se hicieron conscientes bien pronto de que su actuación más eficaz empezaba a ser el cuestionamiento público de los responsables políticos y del funcionamiento de las instituciones, lo que no excluyó las manifestaciones y los encierros que caracterizaron la que dio en llamarse «rebelión de los cojos» ${ }^{101}$.

\section{Agradecimientos}

A las personas que han facilitado sus testimonios y, en particular, a Braulia Ruiz Moreno y Pedro Sergio Moyano por la colaboración en la localización de material e informantes. 
The social sequelae of polio: the beginnings of the associationist movement in Spain (1957-1975)

Juan Antonio Rodríguez Sánchez ..................................

1.- Introduction. 2.-The Association against Polio (ALPE). 3.-The Catholic Fraternity of the Sick and Disabled. 4.-Sickness and disability: perspectives of the associations. 5.-The problems of people with disabilities. 5.1.- Education. 5.2.- Vocational training and employability. 6.-Forms of socialization. 6.1.Active pedagogy. 6.2.-Camps and colonies. 7.- Conclusions.

ABSTRACT: The social response in Spain against the polio epidemic was conditioned by the limitations imposed by the dictatorship. The first associations that emerged were related to the political system or were part of secular movements of the Catholic Church. Among the former is the Association against Polio (ALPE) and among the latter is the Catholic Fraternity of Sick and Disabled People. They offer a contrast in their functions and their model of disability: 
a clear transition from the medical to the social model. A further dilemma detected was whether to offer services or teach people how to claim them. More important was the transmission of a model of sociability (through diocesan and camp activities) that incorporated democratic practices and trained leaders who have played an important role in the associations of people with disabilities since the democratic transition. 